\title{
PERINTISAN PEMBANGUNAN PERPUSTAKAAN MASJID SEBAGAI SARANA BELAJAR MASYARAKAT SEPANJANG HAYAT DI MASJID AL MUAAWANAH SARJAMBE DESA CANGKUANGKECAMATAN LELES KABUPATEN GARUT
}

\author{
Kurniasih, N., Komariah, N., Rachmawati, T.S. dan Rodiah, S. \\ Staf Pengajar Program Studi Ilmu Perpustakaan Fakultas Ilmu Komunikasi Univeritas Padjadjaran
}

\section{RINGKASAN EKSEKUTIF}

Masjid sebagai sarana ibadah bagi umat Islam dengan beragam kegiatan yang diselenggarakannya mencerminkan pentingnya menjaga keseimbangan hubungan dengan Yang Maha Kuasa dan dengan sesama manusia.Fungsi masjid sebagai tempat ibadah dan lembaga dakwah juga tempat bagi jamaahnya belajar di sepanjang hayatnya. Saat ini telah banyak masjid yang dilengkapi berbagai fasilitas pendukung peran masjid, antara lain dengan dibangunnya perpustakaan. Salah satu kampung yang berada di wilayah Desa Cangkuang Garut adalah Kampung Sarjambe yang pernah meraih prestasi sebagai juara kedua Tingkat Provinsi Jawa Barat untuk kategori kegotongroyongan. Kegiatan Pengabdian Kepada Masyarakat (PKM) yang yang telah dilaksanakan berupa rintisan perpustakaan masjid di Masjid Al Muaawanah Sarjambe Desa Cangkuang. Hasil dari kegiatan iniadalah : terwujudnya rintisan perpustakaan masjid berupa 70 buah judul/ eksemplar buku yang telah diolah sesuai dengan kaidah perpustakaan dalam lemari buku yang memadai, dilengkapi pula dengan administrasi buku dan administrasi peminjaman. Para calon pengelola perpustakaan masjid telah paham mengenai peran dan fungsi perpustakaan masjid agar dapat mengelola perpustakaan masjid serta optimalisasi peran tersebut di masyarakat.Untuk menjadikan paham dan terampil dalam mengelola perpustakaan dilakukan pelatihan administrasi perpustakaan dan demonstrasi pembentukkan nomor klasifikasi berdasarkan subjek agar terwujud tertib administrasi dan mempermudah penelusuran serta layanan informasi.

Kata Kunci: perpustakaan masjid, perintisan perpustakaan, tata kelola, sarana belajar

\section{EXECUTIVE SUMMARY}

The mosque as a place of worship for Muslims with a variety of activities that reflect the importance of maintaining the balance of the relations with the Almighty and with fellow human beings. The function of the mosque as a place of worship for Muslims with a variety of activities that reflect the importance of maintaining the balance of the convening of the relationship with the Almighty and with fellow human beings. The function of the mosque as a place of worship and also a propaganda agency for the congregation learned in all his life. When this has been a lot of mosques are equipped with various facilities to support the role of the mosque, among others, with the construction of the library. Kampung Sarjambe Cangkuang is one village in the territory Garut ever have had achievement as the runner up-Levels West Java Province to the category of mutual cooperation. Activities of Community Services (PKM) which has been implemented in the form of a stub library of mosque Al Muaawanah in Sarjambe Cangkuang village. The results of this activity are: the establishment of a pilot library of mosques are 70 pieces of title / copies of the book that has been processed in accordance with the rules of the library, bookcase adequate, equipped with the administration of borrowing books. The candidates mosque library managers have understood about the role and function of the library of the mosque in order to manage the library of the mosque as well as the optimization of his role in society. To make aware and skilled in managing the library with the library administration training,demonstration of formation of classification numbers based on the subject in order to materialize the orderly administration, facilitate search and information service.

Key words: library of mosque, pioneering library, governance, learning tools

\section{PENDAHULUAN}

Masjid selain sebagai tempat beribadah seperti sholat dan membaca Al Qur'an masjid sering dipergunakan untuk kegiatan lain yang bersifat pemberdayaan umat Islam. Aktivitas tersebut menunjukkan bahwa masjid merupakan tempat berbagi ilmu dan belajar sepanjang hayat bagi umat Islam juga merupakan sentral informasi bagi warga sekitarnya. Saat ini telah banyak masjid yang dilengkapi oleh beragam fasilitas untuk mendukung peran masjid dalam upaya pembelajaran umatnya, antara lain dengan dibangunnya perpustakaan masjid. Perpustakaan masjid ini merupakan salah satu sarana dan upaya untuk meningkatkan pengetahuan serta kegemaran membaca sebagai wujud mencerdaskan kehidupan bangsa dan merupakan bagian integral dari kegiatan pembangunan umat Islam.

Perpustakaan masjid dikategorikan sebagai salah satu perpustakaan tempat ibadah atau lembaga keagamaan. Sutarno (2006:52) menyatakan bahwa ada dua pendapat tentang kategori jenis perpustakaan untuk perpustakaan tempat ibadah. Pendapat yang pertama mengatakan bahwa perpustakaan tempat ibadah merupakan perpustakaan khusus, karena koleksinya khusus mengenai agama tertentu dan lokasinya di lingkungan tempat ibadah agama yang bersangkutan.

Adapun perpustakaan masjid tugas dan fungsi utamanya adalah melayani masyarakat dalam hal ini umat Islam, sedangkan tujuan perpustakaan masjid adalah untuk pengembangan pendidikan masyarakat Islam. Siregar (2004) dalam Zuhdi (2010) menyatakan bahwa perpustakaan masjid merupakan bagian yang tak terpisahkan dengan umat Islam sebagai bagian dari proses pendidikan dan peningkatan iman dan taqwa.

Salah satu desa yang menjadi ikon Kabupaten Garut adalah Desa Cangkuang yang berada di wilayah Kecamatan Leles.Desa Cangkuang menjadi terkenal karena di sini terdapat Candi Cangkuang dan Kampung Adat Pulo sebagai objek wisata budaya yang banyak 
dikunjungi wisatawan. Salah satu kampung yang berada di wilayah Desa Cangkuang adalah Kampung Sarjambe. Kampung pada tahun 2014 sebagai perwakilan dari Desa Cangkuang meraih prestasi sebagai juara ke dua tingkat Provinsi Jawa Barat untuk kategori kegotongroyongan. Kampung Sarjambe berpenduduk 1455 jiwa yang terbagi menjadi 2 RW dan 10 RT. Di Kampung Sarjambe terdapat sebuah masjid jami yang bernama Al Muaawanah. Setiap menjelang sholat magrib masyarakat sekitar akan mendatangi masjid untuk melaksanakan sholat magrib berjama'ah dan dilanjutkan dengan membaca al qur'an atau diskusi keagamaan sampai tiba saatnya sholat isya.

Selain untuk melaksanakan ibadah sholat, masjid ini juga dipergunakan untuk kegiatan mempelajari agama Islam seperti melalui majlis ta'lim. Terdapat dua kegiatan majlis ta'lim setiap minggunya, yaitu majlis ta'lim yang dihadiri oleh umum setiap hari Minggu sore, dan majlis ta'lim khusus untuk kaum wanita setiap hari Jumat siang. Disamping itu setiap hari Rabu malam diselenggarakan proses belajar agama Islam yang khusus untuk kaum remaja.

Kira-kira 100 meter dari masjid Al Muaawanah terdapat sebuah bangunan sekolah (madrasah). Madrasah ini pagi hari dipergunakan sebagai tempat belajar anak-anak usia dini (PAUD), sedangkan di siang hari (mulai jam 14.00 sampai jam 16.00) dipergunakan untuk pendidikan agama Islam (madrasah diniyah). Terdapat sekitar 40 orang siswa usia SD yang belajar di madrasah diniyah ini.

Memperhatikan kondisi sekitar dan potensi yang dimiliki oleh Masjid Al Muaawanah Sarjambe, kami tim PKM dari Program Studi Ilmu Perpustakaan berupaya merintis pembangunan perpustakaan masjid sebagai sarana belajar non formal bagi masyarakat di kampung Sarjambe khususnya dan masyarakat di wilayah Desa Cangkuang pada umumnya. Bahkan mungkin akan menginspirasi masjid-masjid yang lain untuk merintis adanya perpustakaan di masjid mereka.

Dengan keberadaan perpustakaan masjid serta pengetahuan dan keterampilan mengelola perpustakaan masjid dapat menggugah kesadaran warga masyarakat di wilayah Sarjambe Cangkuang untuk mendayagunakan semua potensi dan fasilitas yang ada di Masjid Al-Muaawanah seoptimal mungkin.. Peran dan fungsi masjid pun akan semakin beragam dalam memberdayakan masyarakat dalam mewujudkan visi dan misi berdirinya masjid.

\section{SUMBER INSPIRASI}

Masih rendahnya pengetahuan masyarakat desa tentang fungsi keberadaan perpustakaan mesjid, sehingga kami Tim PKM mencoba merintis membangun perpustakaan mesjid tersebut sebagai sarana belajar masyarakat sepanjang hayat, agar Perpustakaan Masjid Al Muawanah di Kampung Sarjambe akan memiliki posisi strategis sebagai tempat disimpannya sumbersumber pengetahuan tentang agama Islam yang bisa dimanfaatkan oleh masyarakat sekitar dalam rangka menambah pengetahuan dan memperdalam agama Islam. Sebagaimana yang dinyatakan oleh Sumpeno (1994) dalam Zuhdi (2010) bahwa tujuan perpustakaan masjid adalah:
1. Menanamkan kecintaan dan kesadaran atas ajaran Islam

2. Memperluas sumber-sumber pengetahuan Islam

3. Menyediakan bahan bacaan yang menyangkut ilmu pengetahuan secara umum

4. Memupuk kegemaran membaca

5. Membantu mengembangkan keterampilan berbahasa

6. Membimbing jamaah menelusur bahan pustaka yang didinginkan.

Dengan keberadaan perpustakaan masjid serta pengetahuan dan keterampilan mengelola perpustakaan masjid dapat menggugah kesadaran warga masyarakat di wilayah Sarjambe Cangkuang untuk mendayagunakan semua potensi dan fasilitas yang ada di Masjid AlMuawanah seoptimal mungkin.. Peran dan fungsi masjid pun akan semakin beragam dalam memberdayakan masyarakat.

Demikian pula halnya keberadaan perpustakaan Masjid Al Muawanah Sarjambe dapat menunjang aktivitas masjid yang selama ini ada seperti ceramah tentang pengetahuan agama Islam melalui majlis ta'lim, dan kajian-kajian khusus tentang agama Islam yang diberikan pada para remaja. Keberadaan perpustakaan di Masjid Al Muawanah dapat memenuhi kehausan masyarakat akan sumber-sumber pengetahuan dalam hal ini buku-buku yang berisi tentang ajaran Islam. Dengan adanya Perpustakaan Masjid Al Muawanah masyarakat Kampung Sarjambe menjadi memiliki tempat untuk mencari buku-buku yang bisa menambah pengetahuan mereka tentang Agama Islam.

\section{METODE}

Metode yang digunakan dalam kegiatan ini adalah kegiatan nyata membangun perpustakaan masjid diikuti dengan pelatihan pengelolaan perpustakaan masjid bagi para calon pengelola perpustakaan masjid. Dalam merintis perpustakaan masjid ini tim PKM membuat rancangan perpustakaan masjid yang disesuaikan dengan situasi dan kondisi masyarakat setempat, berdasarkan hasil diskusi kelompok terpusat (FGD) dengan pengelola masjid.

Perancangan mulai dari penentuan tempat, desain tempat, koleksi yang akan diberikan, tata administrasi pelayanan hingga model layanan perpustakaan.Pelaksanaan melibatkan pengelola masjid dan mahasiswa dari Program Studi Ilmu Perpustakaan Fikom Unpad.

Tahap persiapan, koordinasi internal, dilakukan oleh Tim untuk merencanakan pelaksanaan secara konseptual, operasional, serta job description. Survey lokasi dan perijinanpelaksanaan dengan pengelola masjid untuk penyusunan instrumen kegiatan.Pembuatan instrumen PKM, seperti desain perpustakaan, tata kelola administrasi perpustakaan dan rancangan materi pelatihan.

Untuk masalah pengolahan koleksi serta upaya mempermudah dalam penelusuran dan pelayanan diperlukan pengetahuan tentang pembentukkan nomor klasifikasi. Untuk itu di sampaikan ceramah dan demonstrasi pengertian dan tujuan klasifikasi, 


\begin{tabular}{|c|c|c|c|}
\hline No & Indikator & $\begin{array}{c}\text { Base Line } \\
\text { (sebelum kegiatan) }\end{array}$ & $\begin{array}{c}\text { Pencapaian } \\
\text { (setelah kegiatan) }\end{array}$ \\
\hline 1. & $\begin{array}{l}\text { Perintisan perpustakaan } \\
\text { mesjid }\end{array}$ & $\begin{array}{l}\text { Mesjid Muawanah Sarjambe belum } \\
\text { mempunyai sumber informasi }\end{array}$ & $\begin{array}{l}\text { Terbentuknya perpustakaan masjid dengan rak } \\
\text { buku dan beberapa buku yang telah diolah sebagai } \\
\text { koleksinya serta administrasi penunjang layanan } \\
\text { pengguna perpustakaan mesjid }\end{array}$ \\
\hline 2 & Peran perpustakaan mesjid & $\begin{array}{l}\text { Belum mengetahui peran perpustakaan } \\
\text { masjid dalam pemberdayaan dan sumber } \\
\text { informasi bagi masyarakat }\end{array}$ & $\begin{array}{l}\text { Mengetahui pentingnya perpustakaan masjid } \\
\text { sebagai sarana masyarakat dengan beberapa fungsi } \\
\text { nya antara lain tempat belajar jamaah dan sarana } \\
\text { pengembangan gemar membaca }\end{array}$ \\
\hline 3. & $\begin{array}{l}\text { Pengelola perpustakaan } \\
\text { masjid }\end{array}$ & $\begin{array}{l}\text { Belum paham peran penting dan kebanggaan } \\
\text { sebagai pengelola informasi dalam } \\
\text { mencapai visi misi perpustakaan masjid dan } \\
\text { mempunyai upaya pengembangan diri }\end{array}$ & $\begin{array}{l}\text { Mengetahui peran penting sebagai pengelola } \\
\text { perpustakaan masjid hingga dapat berperan secara } \\
\text { optimal dalam pengembangan perpustakaan mesjid }\end{array}$ \\
\hline 4. & $\begin{array}{l}\text { Administrasi perpustakaan } \\
\text { masjid }\end{array}$ & $\begin{array}{l}\text { Belum paham dan terampil dalam mengelola } \\
\text { administrasi perpustakaan masjid }\end{array}$ & $\begin{array}{l}\text { Paham dan terampil dalam kegiatan administrasi } \\
\text { perpustakaan masjid sebagai upaya tertib } \\
\text { administrasi dan mempermudah penelusuran serta } \\
\text { layanan pengguna perpustakaan }\end{array}$ \\
\hline 5. & $\begin{array}{l}\text { Pembentukkan nomor } \\
\text { klasifikasi }\end{array}$ & $\begin{array}{l}\text { Belum mengetahui adanya perluasan nomor } \\
\text { kelas untuk subjek koleksi agama Islam } \\
(297)\end{array}$ & $\begin{array}{l}\text { Paham dan terampil dalam menentukan nomor kelas } \\
\text { untuk koleksi perpustakaan }\end{array}$ \\
\hline
\end{tabular}

penggunaan sistem klasifikasi persepuluhan Dewey Decimal Classification (DDC). Selain itu dibahas mengenai koleksi subjek Islam yang umumnya dimiliki perpustakaan masjid dan cara menentukan nomor klasifikasi.

\section{KARYA UTAMA}

Sebagai realisasi kegiatan PKM membuat perintisan pembangunan perpustakaan masjid sebagai sarana belajar masyarakat sepanjang hayat di masjid Al Muaawanah Sarjambe Desa Cangkuang kecamatan Leles Kabupaten Garut maka yang utama kami lakukan adalah: Tahap pertama membeli buku-buku untuk koleksi perpustakaan masjid sebagai pemicu perintisan perpustakaan masjid, mengolah buku-buku sesuai standar adminitrasi perpustakaan, membeli rak buku dan menata buku-buku yang telah diolah dalam rak tersebut.

Tahap kedua mengadakan pelatihan Tata Kelola Perpustakaan Masjid, dengan materi peran perpustakaan sekolah beserta contoh-contohnya serta peran pengelola perpustakaan masjid dalam upaya mewujudkan misinya serta upaya pengembangan diri, serta memberikan pemahaman dan keterampilan mengenai administrasi perpustakaan masjid dan pembentukkan nomor kelas dalam upaya tertib administrasi dan memudahkan dalam penelusuran dan pelayanan informasi. Juga kami melakukan bimbingan teknis pelaksanaan hasil pelatihan, sarana konsultasi dan koordinasi.

Hasil Kegiatan Perintisan Perpustakaan Masjid Al-Muaawanah Sarjambe

\section{ULASAN KARYA}

Sebagaimanayang telah dijelaskan diatas, kegiatan PKM ini adalah tentang perintisan pembangunan perpustakaan mesjid sebagai sarana belajar masyarakat sepanjang hayat di mesjid Al Muaawanah Sarjambe desa Cangkuang Kecamatan Leles Kabupaten Garut. Kegiatan pengabdian kepada masyarakat yang telah dilaksanakan memiliki target sebagai berikut:

Terbentuknya Perpustakaan Masjid Al Muawanah meskipun masih sederhana berupa 1 lemari buku lengkap dengan buku-bukunya sebagai koleksi perpustakaan, perintis bagi adanya perpustakaan yang lebih representatif.Koleksi perpustakaan perintis yang didirikan sudah dikelola sesuai dengan kaidah pengelolaan koleksi perpustakaan.Dalam hal ini koleksi buku sudah diberi identitas dan dibuatkan nomor-nomor klasifikasi berdasarkan Dewey Decimal Classification (DDC).Perpustakaan dilengkapi dengan perlengkapan administrasi seperti buku induk, buku anggota, buku peminjaman, stempel untuk identitas buku.

Melalui pelatihan pengelolaan perpustakaan yang diberikan, pengelola perpustakaan masjid mempunyai pengetahuan dan keterampilan dalam mengelola perpustakaan masjid.Pengetahuan mengenai peran perpustakaan masjid bagi umat Islam dan aspek-aspek yang penting diperhatikan dalam upaya pengembangan perpustakaan masjid.Melalui penyampaian materi ini diharapkan para peserta sebagai calon pengelola perpustakaan Masji Al Muawanah memiliki wawasan pengetahuan tentang pentingnya keberadaan perpustakaan masjid.Selain itu disampaikan pengetahuan dan pemahaman mengenai konsep pengelola perpustakaan masjidyangberupaya dapatmewujudkanmisiperpustakaan masjid serta upaya pengembangan diri para pengelolanya. Mengenai manajemen pengelolaannya, diberikan melalui ceramah dan demonstrasi dengan materi administrasi perpustakaan masjid dan pembentukkan nomor klasifikasi sebagai upaya tertib administrasi dan memudahkan dalam penelusuran dan pelayanan informasi.

\section{SIMPULAN}

Pelaksanaan program pengabdian kepada masyarakat (PKM) ini secara keseluruhan telah mencapai target yang telah direncanakan, sebagai berikut :

1. Terwujudnya rintisan perpustakaan masjid, berupa 70 buah judul/ eksemplar buku yang telah diolah sesuai kaidah perpustakaan (diberi tanda identitas perpustakaan, diberi nomor panggil, 
kartu buku dan slip peminjamannya) yang telah ditata dalam lemari buku ditambah dengan kelengkapan administrasinya, yaitu buku induk koleksi dan buku peminjaman koleksi.

2. Para calon pengelola paham peran dan fungsi perpustakaan masjid sehingga dapat mengelola perpustakaan masjid sebagai sarana belajar informal dan berupaya optimalisasi peran tersebut di masyarakat. Selain itu pengelola memperhatikan dengan cermat keempat aspek penting dalam mendukung penyelenggaraan perpustakaan, yaitu koleksi, sumberdaya manusia pengelola perpustakaan, pengguna perpustakaan sebagai sasaran layanan dan fasilitas pendukung.

3. Untuk kebutuhan pengembangan sumber daya manusia dalam hal ini pengelola perpustakaan diberikan pengetahuan dan pemahaman mengenai visi dan misi berdirinya perpustakaan masjid, komponen pendukung perpustakaan masjid hingga bagaimana cara pengembangan diri pengelola perpustakaan upayanya sebagai fasilitator pemberdayaan masyarakat melalui perpustakaan tercapai

4. Untuk menjadikan paham dan terampil dalam mengelola perpustakaan dilakukan pelatihan agar dapat tertib administrasi serta mempermudah kegiatan penelusuran dan layanan informasi dilakukan pelatihan mengenai administrasi perpustakaan masjid. Pelatihan ini ditujukan agar sejak dini rintisan perpustakaan masjid ini telah mempunyai sistem yang baku dalam pergantian pengelola perpustakaan

5. Untuk kebutuhan mengenai pengetahuan perluasan nomor kelas subjek agama Islam, diberikan pelatihan dan demonstrasi mengenai sistem Dewey Decimal Classification (DDC) sebagai pengkategorian koleksi perpustakaan berdasarkan subjeknya, perluasan kelas 297 dan cara pembentukkan nomor kelas.

\section{UCAPAN TERIMA KASIH}

Selama pelaksanaan kegiatan PKM ini dari mulai persiapan, pelaksanaan dilapangan sampai dengan penyusunan laporan akhir ini tidak terlepas dari bantuan dan jasa baik dari berbagai pihak. Oleh karena demikian dengan segala kerendahan hati perkenankanlah kami menyampaikan rasa terima kasih yang sebesar-besarnya kepada Bapak Prof. H. Deddy Mulyana, MA, P.hD, selaku Dekan FIKOM, Wakil Dekan I dan II FIKOM UNPAD yang telah memberikan kesempatan pada kami untuk melaksanakan kegiatan pengabdian pada masyarakat ini, Ketua DKM Masjid Al Muaawanah. adikadik mahasiswi telah membantu mengklasifikasi buku-buku untuk koleksi perpustakaan masjid Al Muawaanah, serta peserta pelatihan manajemen perpustakaan ini sehingga kegiatan PKM ini berjalan lancar beserta seluruh warga yang telah membantu kami dalam menyediakan fasilitas maupun tenaganya sehingga kegiatan ini selesai dilaksanakan.

\section{DAFTAR PUSTAKA}

Bafadal, Ibrahim. 1996. Pengelolaan Perpustakaan Sekolah. Jakarta: Bumi Aksara.

Haryadi, Hendi. 2009. Administrasi Perkantoran untuk Manajer dan Staf. Jakarta: Transmedia Pustaka.

Lasa HS, 2007. Manajemen Perpustakaan Sekolah. Yogyakarta: Pinus

Perpusnas, 2011. Pedoman Umum Penyelenggaraan Perpustakaan Ibadah. Jakarta : Perpusnas RI

Sulistyo-Basuki. 1991. Pengantar Ilmu Perpustakaan. Jakarta: Gramedia Pustaka Utama.

Sutarno NS. 2006. Perpustakaan dan Masyarakat. Jakarta: Sagung Seto.

Undang-undang Nomor 43 Tahun 2007 tentang Perpustakaan

Zuhdi, Muhammad. 2010. Peran Perpustakaan Masjid dalam Mencerdaskan Ummat. Jakarta. 